\title{
Atividades de formulação textual: a correção e as imagens de sujeito projetadas pelos coveiros da cidade de Belém
}

\author{
Activities of textual formulation: the correction and the \\ images of subjects projected from gravediggers of Belém
}

\author{
Anne Carolina Pamplona CHAGAS \\ Universidade Federal do Pará (UFPA) \\ Maria Eulália Sobral TOSCANO \\ Universidade Federal do Pará (UFPA)
}

\begin{abstract}
RESUMO: O objetivo deste artigo é analisar as imagens de sujeitos projetadas pelas correções, enquanto atividade de formulação textual, presentes nas narrativas orais dos coveiros das necrópoles públicas de Belém. É uma pesquisa de base empírico-indutiva, visto que parte de usos reais da língua falada, em contextos específicos de enunciação, conduzida sob uma perspectiva textual-interativa, pois privilegia o discurso como produto de uma atividade interacional. O corpus de análise foi composto de oito entrevistas, realizadas com coveiros das necrópoles públicas de Belém, quais sejam, o cemitério de Santa Izabel e o cemitério de São Jorge, no período de seis a quatorze de junho de 2010. Essas entrevistas foram gravadas em formato A.V.I. (filme Windows) e transcritas com base em normas que registram as marcas de falas comuns à metodologia proposta pela Análise da Conversação (AC) em conversas do cotidiano. Todos os coveiros entrevistados são homens, que concluíram o ensino fundamental e encontravam-se em uma faixa etária que variava de 37 a 57 anos. Em decorrência do fenômeno que se propõe a analisar, essa pesquisa se insere na confluência de estudos desenvolvidos no âmbito da Análise da Conversação, Linguística de Texto e Sociolinguística Interacional.
\end{abstract}

PALAVRAS-CHAVES: Correções. Imagens de Sujeito. Coveiros. Análise da Conversação.

\begin{abstract}
The aim of this paper is to analyze the images of subjects projected by corrections, as textual formulation activities, present in the oral narratives of the gravediggers of public necropolis of Belém. This is a empirical-inductive research, since came from current uses of spoken language in specific contexts of enunciation, conducted under the textualinteractive perspective, and it favors the speech as a product of an interactional activity. The analysis corpus was composed of eight interviews conducted with gravediggers of public necropolis of Belém, named the cemetery of Santa Izabel and the cemetery of São Jorge, from six to fourteen June 2010. These interviews were recorded in AVI (Windows movie) and transcribed based on standards that register the marks of speech according to the methodology proposed by Conversation Analysis (CA) in everyday conversations. All respondents gravediggers are men who completed primary school and were in an age group ranging 37-57 years. From the phenomenon that we aims to analyse, this research is included in the confluence of studies developed by the Conversation Analysis, Linguistic of Text and Interactional Sociolinguistics.

KEYWORDS: Correction. Images of subjects. Gravediggers. Conversation Analysis.
\end{abstract}

\section{Introdução}

Os estudos referentes à modalidade oral da língua têm-se ampliado de modo considerável e, com o surgimento da Análise da Conversação (AC), tornou-se possível estudar o fenômeno da oralidade fora dos "moldes" tradicionais, isto é, os 
métodos utilizados para compreensão da língua escrita e, sobretudo, "desnudar" a tessitura invisível que rege os processos de co-produção discursiva.

A AC tem suas origens no seio da Etnometodologia, com os etnometodólogos norte-americanos Emanuel Schegloff, Harvey Sacks e Gail Jefferson (1974). Ao investigar a linguagem em situações reais de uso e não enunciados isolados de seu contexto de produção, a AC objetiva explicitar os procedimentos utilizados pelos falantes para conduzir suas ações em um evento enunciativo, visando à intercompreensão.

A partir desses estudos preliminares, desenvolveram-se outros de igual importância, os quais ressaltam o aspecto interacional dos encontros sociais. Sob essa ótica, têm-se as pesquisas desenvolvidas pelo sociólogo Erving Goffman (1992), que, sob a perspectiva da dramaturgia, comparou o mundo a um grande palco, no qual o indivíduo, por meio de representações, projeta e regula as imagens (impressões) de si e as que os outros constroem dele. Para ele as imagens podem ser equiparadas a toda e qualquer impressão real ou criada, que os sujeitos projetam dos outros e de si mesmo em uma dada interação.

Dentre as motivações e os porquês para a elaboração do trabalho em questão, bem como de seu tema encontram-se os questionamentos que surgiram após algumas leituras sobre o tema em questão ainda como aluna especial no curso de mestrado da UFPA, tais como: que imagem o sujeito projeta de si durante o processo enunciativo? Que estratégias discursivas nos permitem flagrar essas imagens?

A escolha pelos coveiros, como sujeitos dessa pesquisa surgiu a partir de algumas questões iniciais sobre a profissão, tais como: Se não existem cursos de formação de coveiros, não se nasce coveiro e nem se vira coveiro da noite para o dia. O que faz então um indivíduo vir a ser coveiro? Quais projeções esses atores fazem de si, dos outros e do mundo quando são percebidos e distinguidos como sujeitos de pesquisa? Essas questões, portanto, nos levaram a eleger esses sujeitos (os coveiros), como informantes de minha pesquisa. Essas motivações nos instigaram a investigar a relação desses sujeitos com seu espaço de trabalho, com a sua infância, bem como suas relações interpessoais dentro e fora do contexto do trabalho.

A discussão teórica circunscreve o recorte epistemológico que sustenta esta pesquisa. Neste sentido, a análise proposta pretende evidenciar quais imagens de sujeito são geradas por meio das correções enquanto atividades de formulação textual.

\section{A Construção do texto falado}

Antes dos estudos sobre língua falada tornarem-se um campo fecundo, a fala era considerada equivocadamente como caótica, desorganizada e irregular. Essa visão se dá em função das comparações feitas entre fala e escrita, pois, ao se examinar a fala com os pressupostos referentes à escrita, deixam-se de lado as características essenciais da língua falada, tais como: a quase simultaneidade entre planejamento e verbalização, bem como a simultaneidade entre o tempo de produção e o de recepção do discurso. E, em função dessas singularidades, o falante não dispõe de tempo para revisar seu texto, ou melhor, essa revisão acontece de modo diferenciado, já que é feita no momento da própria interação e na presença do outro.

Segundo Toscano (1999), por meio desse ajustamento feito pelo falante em função da "plateia" para o qual se endereça, é possível verificar a "reflexão sobre o 
fazer [do falante]", evidenciada por meio de atividades linguísticas que têm em vista a intercompreensão.

As especificidades do texto falado derivam, portanto, das circunstâncias de sua produção, ou seja, emergem no seio de uma interação síncrona e das contingências de sua formulação. Segundo a autora, a produção "online" desse texto favorece a dialogicidade, entendida aqui em sentido restrito, como a alternância de turnos durante a interação, que se dá de modo dinâmico.

Além disso, Marcuschi (2002) observa que todo texto falado é fruto de uma co-produção discursiva, o que implica dizer que, mesmo que o locutor detenha a palavra, ele não é o único responsável pela produção de seu discurso, já que ambos falante e ouvinte - se encontram engajados na interlocução e, portanto, produzem conjuntamente a atividade de que participam. Esse engajamento, segundo Marcuschi (2003), permite que os interlocutores sejam cooperativos, co-negociadores e coargumentadores no evento interlocutivo.

Durante o processo de construção do texto falado, criam-se necessidades de ordem pragmática, as quais se sobrepõem muitas vezes às exigências de ordem sintática. Tais necessidades, segundo Koch (2006), são evidenciadas por atividades como truncamentos no fluxo da fala, correções, hesitações, repetições, pausas, paráfrases, aumento no volume entoacional etc.

Ressaltamos, ainda, que, em algumas situações de interação, essas atividades são a serviço da intercompreensão. Ademais elas atuam também na dimensão discursiva, operando a geração de sentidos e de imagens de sujeitos que emergem no decurso do evento comunicativo, tecendo, portanto, a partitura invisível do texto falado (TOSCANO, 1999).

Atualmente, os estudos da fala em interação, segundo Kerbrat-Orecchioni (2006), têm como objeto de estudo a descrição das interações verbais e não verbais em situações cotidianas formais e informais. Por essas razões, na atual conjuntura, afirma-se que o estudo da conversação fundamenta-se no aspecto interacional das relações discursivas, por meio das quais contextos, papéis, tópicos, imagens são negociados. Nesse sentido, a conversação configura-se como um "lugar" primordial das relações sociais.

Marcuschi (2006) explica que os objetos de estudo dos estudos interacionistas são os processos conversacionais, focados na prática do dia-a-dia do ser humano. Para o autor, a conversação seria "uma interação verbal centrada, que se desenvolve durante o tempo em que dois interlocutores voltam a sua atenção visual e cognitiva para uma tarefa comum" (MARCUSCHI, 2006, p. 15) e, por conta disso, os estudos nessa área direcionam-se para os elementos entoacionais, paralinguísticos e contextuais das conversações ditas espontâneas. Segundo Kerbrat-Orecchioni (2006), o objetivo da fala em interação é estudar

(...) [as] regras que sustentam o funcionamento das trocas comunicativas de todos os gêneros; ou, em outros termos, "decifrar a partitura invisível" que orienta [...] o comportamento daqueles que se encontram engajados nessa atividade polifônica complexa que é a condução de uma conversação (KERBRAT-ORECCHIONI, 2006, p. 15).

Portanto, é tarefa dos estudos voltados para a fala em interação analisar as peculiaridades do texto falado, na tentativa de determinar suas características e, importa-lhe, assim, investigar como se dá a elaboração do texto falado, ou seja, as atividades de formulação e, sobretudo, as funções interativas dessas atividades. 
De acordo com Antos (1982, apud FÁVERO, 2005, p. 55), "formular um texto não é só planejá-lo, mas também realizá-lo". Ainda, segundo o referido autor, os dois alicerces da produção de texto são ação e interação. Portanto, sob essa perspectiva, é necessário considerar que os caminhos da conversação não são definidos somente pelo ato enunciativo em si, mas também pela força motriz de todo esse processo: as trocas interativas.

Nos eventos comunicativos, os indivíduos fazem uso das atividades de formulação, as quais, segundo Antos (1982, apud FÁVERO, 2005. p. 52), sempre visam à intercompreensão, pois é a esses procedimentos que esses interlocutores recorrem para resolver, contornar e impedir problemas de compreensão que se manifestam durante o processo interacional.

Nesta atividade de co-produção discursiva, coordenada interativamente, os sujeitos recorrem a atividades linguístico-discursivas que têm em vista a construção do texto. Portanto, urge que se investigue, antes de tudo, de que maneira a produção interacional se constrói coletivamente e, ainda, como tal produção é organizada.

Assim sendo, o texto falado não é caótico e desestruturado, como ainda postulam alguns. Pelo contrário, ele possui uma estrutura própria, a qual é fomentada pelas circunstâncias sociocognitivas de sua produção, que criam necessidades evidenciadas nas atividades de formulação, objeto de reflexão desse estudo.

\subsection{As atividades de formulação textual}

As atividades de formulação são condições de existência do texto. Porém, essas atividades realizam-se de modo diferenciado, em função de sua natureza e peculiaridade.

Assim compreendida, a formulação engloba tanto a rematização frástica: "quando o falante faz avançar as determinações do tema; quanto a rematização parafrástica, quando o falante "limita-se a repisar o que já foi dito" CASTILHO (1998, p. 254). Com base nessas afirmações, Castilho (1998) divide os processos de constituição do texto em:

a) ativação: o processo por meio do qual se introduzem no texto objetosde-discurso;

b) desativação: o processo por meio do qual se abandonam objetos-dediscurso, anteriormente introduzidos, dando origem a digressões e parênteses;

c) reativação: o processo por meio do qual se reintroduzem objetos-dediscurso anteriormente abandonados.

A formulação lato-sensu refere-se a toda e qualquer iniciativa de construção lógico-comunicativa e, no sentido stricto, refere-se às atividades específicas aos quais os sujeitos em interação recorrem para construir adequadamente sua enunciação (TOSCANO, 1999). O que significa dizer que, na acepção estrita, qualquer iniciativa de construção linguística é uma atividade de formulação. Nesse sentido, formular refere, portanto, a totalidade do processo de construção textual.

A formulação stricto sensu diz respeito às atividades de reformulação propriamente ditas, que apresentam um aspecto retrospectivo. Por essa razão, é importante compreender que a reformulação é uma atividade metaformulativa, isto é, ela reformula formulações anteriores na cadeia linear do texto. Nessa perspectiva, a formulação aponta para problemas futuros na interação, já a reformulação provê soluções para enunciados já verbalizados.

Em outros termos, a formulação engloba, em sentido amplo, duas atividades de construção textual diferentes: a formulação e a reformulação. A primeira, segundo 
Hilgert (2002), aponta para a cadeia prospectiva do enunciado, ao passo que a outra aponta para a cadeia retrospectiva. As atividades de formulação e reformulação atuam na elaboração da composição textual, além de disponibilizar, segundo Hilgert (2002), "uma proposta de compreensão" (HILGERT, 2002, p.102) ao interlocutor com quem se interage.

Por isso, as atividades de formulação em sentido lato são os "instrumentos" a que os locutores recorrem para negociar os sentidos de suas interlocuções. E, apesar de apresentarem suas especificidades, as atividades de formulação têm o objetivo de garantir, antes de tudo, a intercompreensão entre os participantes do evento comunicativo (HILGERT, 2002).

Definido o estatuto teórico das atividades de formulação, cabe distinguir, dentre essas atividade formulativas, aquela que interessa ao artigo presente, qual seja, a correção.

\subsection{A correção}

A correção desempenha papel considerável entre os processos de construção do texto falado. Segundo Fávero, Andrade e Aquino (2006), "corrigir é produzir o enunciado linguístico (enunciado - reformulador - ER) que reformula o anterior (enunciado - fonte - EF), considerado 'errado' aos olhos de um dos interlocutores" (FÁVERO, ANDRADE; AQUINO, 2006, p. 258). A correção classifica-se, portanto, como um claro processo de formulação retrospectiva, pois tem como escopo um enunciado anterior.

A correção é, assim, produto de um planejamento local da oralidade, já que o falante recorre, em determinado momento da situação comunicativa, a um outro enunciado, mais condizente com seu projeto de dizer, objetivando, assim, a intercompreensão (FÁVERO, ANDRADE; AQUINO, 2006, p. 273).

Por essa razão, o "erro" deve ser entendido, nessa perspectiva, como uma escolha do falante - lexical, sintática, prosódica e de organização textual ou conversacional - que mesmo já estando posta no discurso, por algum motivo, é considerada, pelo falante ou pelo interlocutor, como inadequada. Logo, é possível afirmar, conforme Fávero, Andrade e Aquino (2006), que "as correções correspondem a um processo altamente interativo e colaborativo, colocando-se como um dispositivo dinâmico, em potencial da língua falada" (FÁVERO, ANDRADE; AQUINO, 2006, p. 273).

No que diz respeito à definição de correção, segundo Toscano (1999), tem-se três posições diferenciadas. A primeira, de Sacks, Schegloff e Jeferson, os quais classificam a correção "como um tipo particular de ocorrências em um conjunto bastante variado de fenômenos, a reparação" (TOSCANO, 1999, p. 49). A segunda, proposta por Barros (1995), que define correção como "um ato de reformulação textual", e a distingue em dois tipos: a reparação e a correção propriamente dita. Para essa autora, a reparação de um modo geral refere-se aos problemas de organização da conversação, isto é, àqueles referentes às violações de regras conversacionais. Já a correção propriamente dita, refere-se aos problemas de ordem fonético-fonológica, morfossintática e semântico-pragmática, isto é, a correção encaixa-se naqueles fenômenos que causam algum tipo de alteração no fluxo da informação ou sequencialidade do texto.

A outra posição é de Fávero, Andrade e Aquino (1998), as autoras "consideram a correção tanto a reformulação textual quanto a reformulação de ações" (TOSCANO, 1999, p.49). Toscano (1999), por sua vez, propõe que se "distingam atos de composição textual de atos reguladores da interação, porquanto se reformulam (no 
sentido de enunciar de novo) enunciados, mas não infrações conversacionais ou ações tidas como inadequadas" (TOSCANO, 1999, p.50). Para Toscano (1999), "qualquer enunciado pode, na verdade, ser alvo de uma correção, basta que o falante indique que ele contrasta com outro, anterior na cadeia linear do texto, constituindo, dessa forma, a formulação pretendida" (TOSCANO, 1999, p.43).

Segundo Toscano (1999), a correção tem sido caracterizada em função dos traços semânticos e formais, aqueles concorrem para criar relação de contraste entre dois enunciados, e estes, por sua vez, materializam-se nas marcas que evidenciam essas relações. $\mathrm{O}$ contraste presente na correção relaciona, portanto, uma formulação $(\mathrm{F} 2)^{1}$ à outra $(\mathrm{F} 1)^{2}$, enunciada anteriormente na cadeia da fala.

No tocante às marcas que sinalizam a correção, Gülich e Kotschi (1987, apud FÁVERO, ANDRADE E AQUINO, 2006, p, 268) afirmam que, por meio de sua presença nos enunciados, é possível conceber os vários tipos de reformulações. A correção é acompanhada de um sinal que indicia seu caráter formulador. Segundo Fávero, Andrade e Aquino (2006), é possível distinguir dois tipos de marcas:

a) as prosódicas: pausas, mudança entoacional, velocidade da elocução, alongamento e intensidade de voz.

b) as discursivas: quer dizer, bom, ah, ah bom, aliás, então, logo, não, ou, ahm, ahm ahm, hein, digamos assim, ou melhor, em outras palavras, perdão, desculpe etc.

Essas marcas (prosódicas e discursivas) se combinam com elementos não verbais, ou seja, se articulam comumente com outras instâncias extralingüísticas, como os gestos, o riso, o olhar.

As autoras afirmam ainda que há diferentes "graus" de contraste, que podem manifestar-se por incompatibilidade sêmica, morfossintática, informacional e segmental ou, simplesmente, por redirecionamento discursivo.

Conforme propõe Toscano (1999), as correções podem ser classificadas segundo "a natureza do erro corrigido, as fontes de produção, a motivação do ato corretor e a distribuição das mesmas na cadeia linear do texto" (TOSCANO, 1999, p. 81). As correções, quanto à "natureza do erro corrigido", classificam-se em gramaticais (fonéticas, morfossintáticas ou semânticas), informacionais (relativas à adequação das informações às representações da realidade objetiva) e pragmáticas (concernentes às alterações no percurso do discurso e às mudanças de atitudes e expressão de sentimentos e opiniões). Quanto à fonte de produção, elas se subdividem em:

a) autocorreção: ocorrem quando a correção (F2) é realizada pelo próprio falante;

b) heterocorreção: quando a correção (F2) é produzida por qualquer locutor exceto por aquele que realizou a primeira formulação $(\mathrm{F} 1)$.

Sobre a motivação para o uso dessas estratégias, tem-se correção automotivada, ou seja, aquela que ocorre por iniciativa própria do falante que corrige; e correção heteromotivada, quando o locutor corrige em função da intervenção do outro.

Por fim, no que diz respeito à distribuição das correções, Toscano (1999) afirma que é possível dividi-las em próximas e distantes. É considerada próxima toda a correção em que (F2) ocorra imediatamente depois de (F1) ou em que, entre elas,

\footnotetext{
${ }^{1}$ Segundo Toscano (1999), F2 refere-se à segunda formulação. (TOSCANO, 1999).

${ }^{2}$ Segundo Toscano (1999), F1 refere-se à primeira formulação. (TOSCANO, 1999).
} 
existam somente marcas e/ou reiteração de (F1); os casos que não satisfazem essas condições devem ser considerados como distantes.

Essa tipologia destaca os pontos que servem como referência, para o estudo da correção e, a partir dela, se torna possível investigar as relações que se estabelecem entre os participantes durante o evento comunicativo, bem como identificar as imagens de sujeitos e de discurso que se projetam ao longo desse evento.

Conforme Fávero, Andrade e Aquino (2006), as correções desempenham ainda diferentes funções interacionais, quais sejam, a busca por cooperação ${ }^{3}$, no caso de heterocorreção, pois ao corrigir seu interlocutor, o falante encontra uma oportunidade de participar ativamente da conversa, já que nesse momento ele coopera para o desenvolvimento da interação - seja demonstrando seu envolvimento com o ouvinte ou sua atenção e interesse pelo que o outro tem a dizer; e a busca por intercompreensão, pois o falante que corrige pretende levar o ouvinte a compreender melhor seu projeto de dizer.

Ressalta-se também que, por meio da correção, o falante pode orientar o foco para o tópico discursivo e para as relações entre os interlocutores, podendo, nesse sentido, ser um recurso de preservação da autoimagem pública e da manutenção da face.

Ressaltamos, de igual modo, que a heterocorreção pode apresentar, dependendo do contexto de interação, um potencial ameaçador de face, já que ela nega o desejo de reconhecimento e aceitação do falante que proferiu o enunciado a princípio equivocado.

Essa atividades de formulação, observada sob uma ótica discursiva, está a serviço da criação de uma "teia de imagens" projetadas pelo sujeito, durante o processo interacional, as quais evidenciam o próprio "eu" e como se dão suas relações interpessoais.

\subsection{Interação: o jogo de imagens}

Goffman (1992), para os estudos conversacionais, ficou conhecido como grande colaborador dos estudos e pesquisas sobre as interações face a face, além de discutir noções cruciais para as análises conversacionais, tais como: interação focalizada, interação desfocalizada, enquadre, alinhamento etc.

Para ele, toda a atividade de um indivíduo em interação gera imagens de sujeitos. Segundo Santayana (1922, apud GOFFMAN, 1992, p.7): “as imagens (máscaras) são expressões controladas e ecos admiráveis do sentimento, ao mesmo tempo fiéis, discretas e supremas (...) são melhor dirigidas ao olhar e mais abertas à observação". Segundo Park (1950, apud GOFMAN,1992), as imagens seriam literalmente máscaras que representam a concepção que formamos de nós mesmos. Para ele,

Não é provavelmente um mero acidente histórico que a palavra "pessoa", em sua acepção primeira, queira dizer máscara. Mas, antes, o reconhecimento do fato de que todo homem está sempre e em todo lugar, mais ou menos conscientemente, representando um papel [...] É nesses papéis que nos conhecemos uns aos outros; é

\footnotetext{
${ }^{3}$ A noção de cooperação adotada neste estudo refere-se à ideia de que cooperar é estar em interação, ou seja, é mostrar-se engajado no ato conversacional e, por esse motivo, o ato de corrigir, também pode ser compreendido como uma cooperação.
} 
nesses papéis que nos conhecemos a nós mesmos (PARK, 1950 apud, GOFFMAN, 1992, p. 27).

Portanto, a máscara (imagem) projetada, seria nosso mais puro "eu", aquilo que verdadeiramente gostaríamos de ser, uma parte integrante de nossa personalidade.

Para Goffman (1992), as imagens podem ser equiparadas a toda e qualquer impressão real ou criada, que os sujeitos projetam dos outros e de si mesmo em uma dada interação. Segundo o autor, em toda interação há um constante jogo de imagens, ou seja, em um evento comunicativo, o falante faz uso de procedimentos linguísticodiscursivos que revelam como ele se concebe e concebe o outro.

Segundo Toscano (1999), partindo da perspectiva dramatúrgica, Goffman assemelha o mundo a um grande palco, no qual o indivíduo encena papéis, em conformidade com a situação social que se lhe coloca. Dessa forma, o perfil enunciativo de cada sujeito seria múltiplo e multifacetado, pois as "encenações" refletiriam uma dada situação enunciativa. Isso diferencia o indivíduo ator do ator propriamente dito, já que o ator recebe o "papel" previamente, bem como seus textos e, por isso, precisa desenvolver trejeitos nos chamados laboratórios, o que não ocorre com o indivíduo ator, que precisa encenar cotidianamente e, diferentemente do outro, não passa por laboratórios, pois, no caso deste, o discurso é construído e coconstruído no momento da interação e na/pela relação com o outro.

Por essa razão, Goffman (1992) afirma que as imagens projetadas pelos indivíduos emergem como um mosaico, o qual se constrói a partir das diferentes interações. Isso se deve ao fato de que, para o referido autor, a própria vida pode ser comparada a uma encenação dramática. Nesse sentido, Goffman (1992) afirma que,

A noção geral de que fazemos uma representação de nós mesmos para os outros não é nenhuma novidade. O que deveria ser acentuado, para concluir, é que a própria estrutura do "eu" pode ser considerada segundo o modo como nos arranjamos para executar estas representações na sociedade (GOFFMAN, 1992, p. 230).

Portanto, as representações que fazemos de nós para os outros e para nós mesmos, fundamentam a estrutura de nosso "eu". Logo, a própria noção do "eu" é arranjada, uma vez que tal estrutura é determinada pelos desdobramentos que fazemos em uma dada realidade enunciativa. Em suma, o próprio "eu" existe e forma-se em função das impressões, estas determinam as representações que serão executadas ou não. E as representações que fazemos, por sua vez, além de acentuar certos aspectos e dissimular outros, dizem da nossa essência, do nosso "eu".

No estudo proposto por Goffman (1992), a personalidade encenada é considerada uma imagem já que, em sociedade "o personagem que alguém representa e o próprio indivíduo são, de certa forma, equiparados" (Goffman, 1992, p. 231). Em função dessa comparação, o "eu", como personagem representado, não é algo orgânico que pode ser facilmente definido, ele é, segundo Goffman (1992), um "efeito dramático" que surge de uma determinada situação. Por essa razão, as imagens projetadas nem sempre podem ser atribuídas apenas ao seu possuidor (indivíduo), mas à situação inteira e a tudo que a constitui.

Segundo Goffman (1992), o "eu" é diferente do seu possuidor, já que o possuidor é apenas o corpo, a pessoa física, ou ainda o "cabide" onde se pendura por algum tempo uma dada impressão criada colaborativamente. Por isso, os meios para produzir ou projetar diferentes "eus" não residem no próprio indivíduo, mas sim nas diversas atividades, nos eventos sociais e, sobretudo, na relação com o outro, pois quando um indivíduo se apresenta diante dos outros, consciente ou 
inconscientemente, ele projeta uma definição da situação, da qual uma parte importante é a percepção de si mesmo.

Conforme Goffman (1992), durante o processo interacional, são empregadas a todo o momento práticas preventivas as quais tem por objetivo auxiliar os interactantes a evitar situações embaraçosas, e também práticas corretivas, as quais são utilizadas "para compensar as ocorrências desabonadoras que não tenham sido evitadas com sucesso" (GOFFMAN, 1992, p.22). Fala-se ainda em práticas protetoras ou "diplomacia", ou seja, aquelas que um participante emprega para salvaguardar a definição projetada pelo outro.

Toscano (1999) afirma, com base em Goffman (1992), que quando um indivíduo executa um determinado "papel", lança mão de várias práticas defensivas para salvaguardar a imagem que ele projeta para os participantes com os quais interage. E, ao valer-se de práticas corretoras e protetoras, o indivíduo projeta impressões de si mesmo e do outro, o que, por sua vez, pode (des) construir imagens (in) desejadas de si e do outro.

Segundo Park (1950, apud GOFFMAN, 1992, p. 27), a partir do momento em que o sujeito enuncia, mostra-se ao outro e a si mesmo, já que essa "encenação" representa a concepção de si e do papel que ele assume. Essas representações se constroem por meio da "fachada", ou seja, "o equipamento expressivo de tipo padronizado intencional ou inconscientemente empregado pelo indivíduo durante a representação" (GOFFMAN, 1992, p.29). Tais fachadas podem ser classificadas por meio do cenário - a mobília, a decoração, a disposição física e outros elementos do pano de fundo que constituirão o suporte para o palco. Há ainda, a fachada pessoal, ou seja, os sinais que marcam a fachada do próprio ator, tais como: sexo, vestuário, idade, raça, altura, atitude, expressões faciais, gestos etc.

Nesse sentido, Goffman (1992) afirma, ainda, que é conveniente dividir os estímulos ${ }^{4}$ que formam a fachada pessoal em:

a) aparência: funcionam em um determinado momento para revelar o status social do ato;

b) maneira: informam sobre o papel que o ator desempenha, em determinada situação.

As fachadas, por sua vez, modificam-se em função dos contextos interacionais e são uma consequência natural da organização social.

Segundo Goffman (1992), o indivíduo trabalha para preservar sua imagem, realizando o que Kerbrat-Orecchioni (2006) chama de "trabalho de figuração" (face work), isto é, "tudo o que uma pessoa empreende para que suas ações não impliquem perda diante de ninguém (nem de si mesma)" (KERBRAT-ORECCHIONI, 2006, p. $80)$.

Assim, quando uma pessoa chega à presença de outra(s), pode existir alguma explicação para que ela atue do modo como lhe convém, naquela situação comunicativa, de forma que consiga projetar a impressão que lhe é conveniente (GOFFMAN, 1992). Às vezes, ela agirá de modo calculado, expressando-se de determinada maneira para causar a impressão que lhe interessa; outras vezes, mesmo agindo de modo calculado, ela terá pouca consciência do que faz; ou ainda, agirá intencionalmente, por talvez querer refletir a tradição do grupo ao qual pertence, ou não (GOFFMAN, 1992).

Esse "controle" sobre si restabelece, segundo o referido autor, "a simetria do processo de comunicação e monta o palco para um tipo de jogo de informação, um

\footnotetext{
${ }^{4}$ Segundo Goffman (1992) aparência e maneira podem ser consideradas "estímulos", pois são sinais relativamente móveis e transitórios, os quais podem variar, na representação, de um momento a outro.
} 
ciclo potencialmente infinito de encobrimento, revelações falsas e redescobertas". (GOFFMAN, 1992, p.17). Essa noção de simetria mencionada pelo autor é por vezes mantida em função do chamado "consenso operacional", isto é, deve haver certo respeito entre os interactantes mesmo que as opiniões divirjam.

É possível afirmar que, em todo processo interacional, há a priori uma projeção inicial, que pode sofrer alterações e acréscimos ao longo da interação. Mas, uma vez já iniciada a interação, as projeções iniciais raramente são completamente descartadas, pois, segundo Goffman (1992), "na vida cotidiana, há uma clara compreensão de que as primeiras impressões são importantes" (GOFFMAN, 1992, p. 19).

Essas considerações de Goffman parecem confirmar o dito popular de que "a primeira impressão é a que fica", e as primeiras impressões dentro do jogo interacional são muito importantes para a compreensão das imagens de sujeito que se projetam ao longo do evento comunicativo.

Segundo Goffman (1992), dois princípios básicos, estruturadores das relações conversacionais, orientam o comportamento dos indivíduos em uma situação social:

1. a partir do momento que um indivíduo se projeta de determinada maneira, ele tem o direito moral de esperar que os outros o valorizem e o tratem da maneira esperada;

2. toda pessoa deve parecer o que de fato é, ou pelo menos o que demonstra ser implicitamente ou explicitamente.

Por fim, afirma-se que, sob essa perspectiva, o indivíduo é representado por duas partes: a primeira que se refere à posição de ator - um produtor e fabricante de impressões; e a segunda, que diz respeito à posição de personagem, ou seja, a representação do próprio indivíduo - "o eu", portanto, como personagem representado, o qual tem por interesse primordial, na geração das impressões manifestadas ao longo do evento comunicativo, "saber se será acreditado ou desacreditado" (GOFFMAN, 1992, p. 231).

Segundo Goffman (1992), como seres humanos temos impulsos variados, estados de espíritos múltiplos que se alteram de um momento para o outro. Entretanto, quando nos revestimos de personagem diante de um determinado público, devemos “controlar" esses comportamentos sujeitos a altos e baixos, já que, é mais viável manter uma representação, de certa forma, homogênea. Segundo Santayana (1922, apud GOFFMAN, 1992), isso se deve ao fato de que "o processo de socialização não apenas transfigura, mas também fixa" (SANTAYANA 1922, apud GOFFMAN, 1992, p. 58) condutas e imagens projetadas.

Em suma, os estudos desenvolvidos por Goffman são de extrema relevância para compreender os meandros da fala em interação, bem como para desvelar os recursos e estratégias utilizados pelos interactantes para (des)construir imagens de si, dos outros e da situação enunciativa.

\subsection{A Correção e as imagens de sujeito}

A correção apresenta um papel considerável nos processos de construção do texto falado. Segundo Fávero, Andrade e Aquino (2006), corrigir é produzir um determinado enunciado linguístico (ER) ${ }^{5}$ que reformula o anterior (EF) ${ }^{6}$, considerado equivocado aos olhos do interlocutor. A correção classifica-se como um

\footnotetext{
${ }^{5}$ Segundo Fávero, Andrade e Aquino (2006) ER equivale a enunciado reformulador.

${ }^{6}$ Segundo Fávero, Andrade e Aquino (2006) EF equivale a enunciado fonte.
} 
claro processo de formulação retrospectiva, pois tem como escopo um enunciado já verbalizado.

Quanto às funções das correções, de modo geral, temos a macro função de garantir a intercompreensão entre os falantes. Além dessa função, há outras consideradas pontuais, tais como a função textual de precisão referencial e a função pragmática de demonstrar mudança de atitude do falante em relação ao conteúdo da proposição.

A propósito, observe as correções nos fragmentos, a seguir:

\section{FRAGMENTO 11}

D2: vocês chegam a comentar:: é::: a morte de alguém que vocês enterraram? com outro::: outro parceiro... outro companhei:::ro?

$\mathrm{V}$ : às vezes é:: a gente comenta assim::: ainda mais assim:: quando vai fazer sepultamento assim::: que a pessoa é muito... grande::: assim:: que... num dá ai:: na sepultura sabe?Como

125 tivemos essa semana que passou... não... segunda feira... segunda?... foi:: segunda... foi ontem... que nós enterramos três que::: todos três tivemos que::: rasgar a parede da sepultura porque não dava... eram muito gordo...

No fragmento (11), o locutor $V$ responde uma pergunta sobre as conversas que ocorrem durante ou após os sepultamentos realizados e, em sua resposta, corrige "essa semana que passou" por "segunda feira". Trata-se de uma autocorreção motivada pelo próprio falante, evidenciada linguisticamente por uma marca prototípica de correção, a negação "não”, localizada entre EF e ER.

A correção identificada tem por função garantir a precisão referencial, pois o sujeito V "trabalha" a serviço das informações que compõem o conteúdo de seu discurso. Ao fazer uso da correção, o falante manifesta sua "preocupação" no que tange aos acontecimentos narrados, e corrige EF, na tentativa de ser mais fidedigno a eles.

Ao se corrigir, ele projeta a imagem de um sujeito que "trabalha" para prover informações "verdadeiras" e, consequentemente, um sujeito preocupado com sua autoimagem pública.

A seguir, temos outros exemplos de autocorreção com a função de garantir a precisão referencial:

\section{FRAGMENTO 12}

D1: cada dia é uma...

$185 \mathrm{~J}$ : logo quando eu entrei de coveiro aqui... nesse cemitério... o meu primeiro sepultamento que eu fui fazer... na verdade... eu não fui fazer o sepultamento... eu fui fazer uma exumação:... fui retirar né... pra... pra levar pra outro lugar... e eu fiquei::... eu fiquei eh::.... tão coisa assim... de vê que:: era trinta anos que tava enterrado... o corpo do coronel fon/o coronel Barata... num sei se vocês já ouviram falar...

$(20102 J)$

No fragmento (12), o sujeito $\mathrm{J}$ discorre sobre o que acha de seu local de trabalho, o cemitério e, em seu relato, efetua uma correção, substituindo "sepultamento" por "exumação". Tal correção é reforçada pela negação do EF, por meio da expressão "eu não fui fazer o sepultamento", localizada entre o EF e o ER.

Neste sentido, percebe-se ainda que o sujeito vale-se da expressão "na verdade", localizada entre o $\mathrm{EF}$ e o $\mathrm{ER}$, que, neste caso, anuncia a correção, que acorrerá posteriormente, ou seja, essa expressão ratifica a afirmação de Fávero, Andrade e Aquino (2006) de que a correção pode vir acompanhada de uma marca discursiva ou prosódica que indique seu caráter reformulador. 
Ao corrigir, o interactante busca a intercompreensão, porquanto pretende precisar que o fato relatado refere-se a uma exumação. A correção, neste caso, também projeta a imagem de um sujeito que "trabalha" para ser "fiel" aos acontecimentos e, consequentemente, que espera ser considerado "digno de confiança".

Apresentam-se, a seguir, os últimos exemplos de autocorreção com a função de garantir a precisão referencial:

\section{FRAGMENTO 15}

D1: ah tah::: e como foi que o senhor se tornou coveiro?

JS: [...]... e.:. já depois de eu conhecendo um administrador aqui... por nome Fernando...

50 que era muito meu amigo ele... era não... é né:.... e ele... me passou... pra trabalhar de coveiro... até porque... ele dizia que::.. ele queria que... que ele tivesse trabalhando de dia que... ele gostava de mim né::... aí... ele que me passou pra trabalhar de coveiro...

(20103JS)

Neste fragmento, o sujeito JS responde a pergunta "como você se tornou coveiro?" e, em sua resposta, corrige o EF "era" pelo ER "é".

Ao valer-se da correção, o falante facilita a compreensão do outro sobre a temporalidade dos fatos narrados e ressalta os vínculos de amizade de longas datas que mantém com o sujeito que refere em sua fala, o administrador.

A correção projeta, portanto, a imagem de um sujeito preocupado com sua autoimagem pública, uma vez que demonstra a preocupação deste com a precisão referencial do discurso que constrói.

No fragmento (17), o sujeito $\mathrm{J}$ também discorre sobre a possibilidade de prestar outros serviços no cemitério:

\section{FRAGMENTO 17}

255 D1: então quer dizer que o senhor num presta serviço como:.... letreiro... como... eh::... zelador... ou já prestou... nunca prestou?

J: não... tem colegas ai que... fazem isso né... digamos né:... o coveiro... mas eu:.... eu também não quero ser melhor de que ninguém... mas eu:.... sô... eu acho que eu sou o único coveiro que... não se entrosa né:: digamos assim... nesses... nessas outras áreas.. né...

Durante a resposta de J, há a correção do EF “mas eu sou” pelo ER "eu acho que eu sou". Nesse caso, o locutor corrige EF pelo ER com a finalidade de preservar sua face, pois a correção tem por objetivo mitigar a força ilocucionária da afirmação verbalizada e enquadrar o enunciado como uma questão de opinião. Nota-se, portanto, que, neste caso, a correção tem a função pragmática de expressar mudança de atitude do falante em relação ao que afirma.

Com isso, o falante projeta a imagem de um sujeito menos taxativo, já que enquadra o conteúdo de sua proposição como uma questão de opinião, reduzindo, por sua vez, seu comprometimento em relação ao estado de coisas referido no e pelo discurso.

Além das autocorreções, foram identificados exemplos de heterocorreções com função de garantir a precisão referencial, como vemos nos fragmentos 


\section{FRAGMENTO 18}

D1: então o senhor era uma criança assim:: que:: brincava aqui pelos arredores do cemitério

$\mathrm{V}$ : arredores do cemitério... me criei dentro do cemitério

$(20101 \mathrm{~V})$

No fragmento (18), o locutor V corrige o enunciado "arredores do cemitério", produzido pelo interlocutor por "dentro do cemitério", para precisar o referente, já que as informações contidas no EF, não correspondem às representações da realidade objetiva dos fatos.

Neste caso, o falante $\mathrm{V}$ primeiramente incorpora o enunciado matriz "arredores do cemitério" proposto pelo interlocutor, isto é, reconhece-o e valoriza-o, para só depois, corrigi-lo pela expressão “dentro do cemitério”. Nesse sentido, a R projeta a imagem de um sujeito preocupado em ser fidedigno às representações dos estados referidos no discurso.

No fragmento (19), o sujeito responde a uma pergunta sobre o motivo das constantes visitas a determinadas sepulturas e, em sua resposta, ele corrige a contribuição do interlocutor (D1):

\section{FRAGMENTO 19}

J: isso... entendeu... bota as plaquinhas... né:: de graça alcançada... estudante né:.... vai lá através daquela pessoa... cria uma fé né... e:.... consegue e... depois vem pagar... a sua... a sua...

D1: a sua graça..

$\mathrm{J}$ : a sua graça né... a sua dívida... aquela pedrinha ali com o nome...

A exemplo do fragmento anterior, o locutor $\mathrm{J}$ primeiramente incorpora a contribuição do interlocutor por meio da repetição do EF "a sua graça", para somente depois corrigi-la pelo ER "a sua divida".

A repetição do enunciado "a sua graça" evidencia o reconhecimento do outro, constituindo assim, uma estratégia que prefacia o ato ameaçador de face, a heterocorreção. Neste caso, a correção projeta a imagem de um sujeito que quer mostrar fidedignidade no provimento das informações.

A análise nos permite observar que a correção pode assumir funções diferenciadas, se considerarmos a natureza do erro: informacional (correções com função de precisão referencial) ou pragmático (correções com função de demonstrar mudança de atitude do falante). Com base nesses tipos de erros e suas respectivas funções, projetam-se imagens de sujeito diferenciadas, conforme se observa no quadro a seguir:

Quadro 1: Ocorrências de Correção no corpus

\begin{tabular}{|c|l|l|}
\hline \multicolumn{1}{|c|}{$\begin{array}{c}\text { FONTE DE } \\
\text { PRODUÇÃO }\end{array}$} & \multicolumn{1}{|c|}{ FUNÇÃO } & IMAGENS PROJETADAS \\
\hline AUTOCORREÇÕES & precisão referencial & $\begin{array}{l}\text { sujeito preocupado em ser } \\
\text { fidedigno no provimento das } \\
\text { informações, sujeito preocupado } \\
\text { com sua autoimagem pública }\end{array}$ \\
\cline { 2 - 3 } & $\begin{array}{l}\text { demonstrar mudança } \\
\text { de atitude }\end{array}$ & \multicolumn{1}{|c|}{ sujeito menos taxativo } \\
\hline HETEROCORREÇÕES & precisão referencial & $\begin{array}{l}\text { sujeito preocupado em ser } \\
\text { fidedigno às representações dos }\end{array}$ \\
\hline
\end{tabular}




\section{Fonte: Análise dos dados, 2011.}

De acordo com o quadro acima, as autocorreções com a função de precisão referencial são motivadas, neste corpus, por erros informacionais, ou seja, são relativas à adequação das informações às representações dos fatos narrados. Por esse motivo, as imagens de sujeito projetadas pelas correções informacionais correlacionam-se a "ser verdadeiro", "ser fidedigno" aos estados de coisas discursivizado, e, em consequência, "ser acreditado" pelo outro.

As autocorreções com a função de demonstrar mudança de atitude do falante foram motivadas por erros pragmáticos, os quais se referem, neste caso, às alterações de atitude, expressões de sentimentos e opiniões. Nesse sentido, projetou-se a imagem de um sujeito menos taxativo, atento, portanto, às relações intersubjetivas que se constroem no decurso da interação.

As heterocorreções, identificadas no corpus, buscam assegurar a precisão referencial, pois o falante corrige as informações propostas por D1 por elas não condizerem com a realidade objetiva dos fatos narrados. Por essa razão, projetou-se a imagem de sujeito preocupado em ser fidedigno nos provimento das informações.

As heterocorreções identificadas no corpus, apresentaram pouca frequência e quando ocorreram, foram prefaciadas por estratégias de polidez, já que neste contexto de interação (uma entrevista), as heterocorreções podem apresentar um potencial ameaçador de face.

\section{Algumas Considerações}

Considerando os objetivos a que este estudo se propôs, verifica-se que, de maneira geral, eles foram atingidos, ou seja, apontaram-se as imagens de sujeito projetadas pelas correções presentes no discurso dos coveiros dos cemitérios públicos de Belém. Ademais, destacou-se a correlação entre as imagens de sujeito projetadas pelos coveiros das necrópoles públicas de Belém e a correção enquanto atividade de formulação textual, tendo em vista as relações interpessoais estabelecidas e o contexto de enunciação.

O recorte teórico escolhido possibilitou, de certa forma, um tratamento satisfatório quanto ao estudo das imagens de sujeito projetadas diante de si e do outro em situações reais de uso da língua falada. Essas imagens foram observadas a partir das correções, que evidenciaram, por sua vez, como o sujeito se concebe e concebe o outro a partir do contexto interacional, da entrevista. Nesse sentido, é possível afirmar que, os meios para projetar diferentes imagens não residem no próprio indivíduo, mas na relação como outro nas diversas atividades e situações sociais, a que os falantes estão engajados.

Uma observação de suma importância que precisa ser explicitada, refere-se à ocorrência e frequência de heterocorreções no corpus analisado. $\mathrm{Na}$ verdade, foi possível perceber que as heterocorreções, presentes nos corpus, tiveram sua força ilocucionária mitigada, ou seja, elas foram prefaciadas por estratégias de polidez. Isso se deve ao potencial ameaçador de face das heterocorreções em contextos formais de interação, em que os interactantes mantêm vínculos de amizade pouco estreitos, no caso da pesquisa em questão, o vínculo entre entrevistador e entrevistado eram tênues, o que confirma essa assertiva. 
No quadro geral das interações, a correção, enquanto as atividade formulativa, revelou-se bastante produtiva na geração de imagens de sujeito, evidenciando que a formulação é orientada por desejos de si e do outro. Ao introduzir tais questões, refletimos sobre o papel que a situação social desempenha na comunicação face a face.

De um modo geral, as imagens de sujeito, projetadas pelos coveiros, foram produzidas em função das necessidades textuais ou discursivas dos falantes. Nesse sentido, as imagens identificadas foram "fruto" ou do contexto interacional e relações interpessoais estabelecidas ou do "esforço" em planejar melhor seu discurso e participação na interação.

Acreditamos que ainda há muito o que se investigar no que tange à relação entre geração de imagens e atividades de formulação; estudos que correlacionem os diversos contextos enunciativos em que os indivíduos estão engajados, com as impressões que se projetam no discurso e por meio dele. Essa correlação poderia, de certa forma, auxiliar na compreensão dos aspectos que motivam a projeção de determinadas imagens de sujeito, em situações reais e específicas de uso da língua falada. Por ora, interessou, a este trabalho, tratar apenas das imagens projetadas pelos coveiros dos cemitérios públicos de Belém, por meio de atividades de formulação textual, no contexto de uma entrevista.

Essa pesquisa pretendeu ser uma contribuição aos estudos referentes à modalidade oral da língua falada em contextos reais de uso, promovendo reflexões sobre a relação entre imagens de sujeito e atividades de formulação textual. Não se trata de um estudo exaustivo, nem de um "olhar" único sobre as representações que os sujeitos fazem de si e dos outros, mas, certamente, um caminho possível.

\section{REFERÊNCIAS BIBLIOGRÁFICAS}

BARROS, D.L.P. Procedimentos de reformulação: a correção. In: PRETI, D. (org.) Análise de textos orais. $2^{\mathrm{a}}$ Ed. São Paulo: FFLCH\USP, 1995 (PROJETOS PARALELOS: V.1).

CASTILHO, A.T de. A língua falada no ensino do português. São Paulo: Contexto, 1998. FÁVERO, L. L.; ANDRADE, M.L. da C. O.; AQUINO, Z.G. O. Atividades de Reformulação III. In: Oralidade e Escrita: perspectiva para o ensino de língua. São Paulo: Cortes, 2005.

Correção. In: JUBRAN, C. C. A. S.; KOCH, I. V. (org.). Gramática do português culto falado no Brasil. Campinas, SP: Editora da Unicamp, 2006.

GOFFMAN, E. A representação do eu na vida cotidiana. (M.C.S. Raposo, Trad.). $9^{\text {a }}$ Ed. Petrópolis, RJ: Vozes, 1992.

HILGERT, J.G. (1993) Esboço de uma fundamentação teórica para o estudo das atividades de formulação textual. In: CASTILHO, A. T. de (org.) Gramática do português falado, vol. III: As abordagens. Campinas. São Paulo: Editora da Unicamp\FAPESP, 2002.

KERBRAT-ORECCHIONI, C. Análise da Conversação: princípios e métodos. São Paulo: Parábola, Editorial, 2006.

KOCH, I. V. SILVA. M. C. P. de S. Especificidade do texto falado. In: JUBRAN, C. C. A. S.; KOCH, I. V. (org.). Gramática do português culto falado no Brasil. Campinas, SP: Editora da Unicamp, 2006.

MARCUSHI, L.A. Análise da Conversação. São Paulo: Ática, 2003. 
A repetição na língua falada como estratégia de formulação textual. In: KOCH. I. V. (org.) Gramática do português falado, vol. VI: Desenvolvimentos. Campinas. São Paulo: Editora da Unicamp\FAPESP, 2002.

.Hesitação. In: JUBRAN, C. C. A. S.; KOCH, I. V. (org.). Gramática do português culto falado no Brasil. Campinas, SP: Editora da Unicamp, 2006. TOSCANO, M.E.S. A construção do texto falado e a produção dos sentidos: o caso da correção. São Paulo: USP, 1999. Tese de doutoramento. 